\title{
SOME BIOLOGICAL PRINCIPLES OF ANIMAL BREEDING
}

\author{
W. J. Casth: \\ Bussey Institution, Forcst Hills, MLassachusetts
}

Animal breeding is the most ancient of all arts. Its beginnings antedate civilization, going back to a time when man lived as the beasts of prey live, subsisting upon such animals as he could catch or kill. As man increased the game began to decrease, and the more provident would keep alive for a time the young of their favorite animal, when taken, until these young had grown larger and would yield more food. Often no doubt, a feeling of attachment grew up hetween captor and captive and the day of slaughter was postponed until the captive had reached breeding age. If young were born in captivity, the thought must at once have occurred to the observer, "Here is an easier and more sure way of getting food than by hunting; why not raise cattle and sheep rather than hunt them." But not all men reasoned thus or, if they did, abandoned the chase, for this continued with increased vigor. The game grew scarcer and wilder and was pursued into less accessible places. Horses and wild dogs were employed to aid in the chase. Wild cattle were hunted to death and wholly exterminated, and wild sheep were almost exterminated. The disappearance of the wild form gave impetus to the propagation of the tame one. Thus the pastoral stage of man's existence was reached. He moved from place to place in scarch of forage for his flocks and herds, the dog and the horse being his assistants. The most important of our domesticated animals tracc back their existence to this stage of culture. The flocks and hercls furnished flesh, milk, clothing and shelter; the horse transportation; the dog defense, aid in the care of the flock, and, not least, companionship. Under the open sky, watching the stars by night and the changing seasons by day, man laid the foundation of the first science, astronomy. In the fertile river valleys, he found he could raise food for himsclf and his animals when the supply on the plains grew short. Thus agriculture began. It necessitated fixed ahode in one spot, regulations as to land-tenure, irrigation; and the like. New uses were now found for the animals; the ox was yoked to the plow, and the horse was harnessed. Thus civilization began, largely through the instrumentality of domesticated animals.

Though animal breeding is the oldest and most fundamental of the arts, its practise down to the present time has been almost wholly 
empirical. A science of animal breeding scarely yet exists, not because thoughtful men have failed to give attention to the subject but rather because of its inherent difficulty. We breed animals as our fathers and grandfathers did because their time-honored methods succeed and we know of no reason for changing those methods. Indeed we can not cxpect to improve them in a rational way until we learn why certain methods succeed and why others fail. Such knowledge of the underlying reasons for successful practise will when secured constitute a science of animal breeding.

The technique of successful animal breeding is difficult and special in the case of each kind of domesticated animal and can best be learned from an apprenticeship on a farm or study in a farm school. The general principles empirically deduced from centuries of practise may be concisely stated thus:

(1) Like begets like, hence the breeder must select for propagation the type of animal he desires to perpetuate.

(2) Pedigree counts. The desired type is more certain to occur among the offspring, if it has occurred repeatedly among the ancestors.

(3) Inbreeding brings uniformity of type but causes loss of vigor.

(4) Crossbreeding increases vigor but destroys uniformity of type.

No one of these generalizations is universally true. To state the recognized limitations and exceptions would be to recapitulate the literature of breeding with the omission only of its technique. The new science of genetics is concerned with the discovery of the reasons for these four empirical generalizations and their various exceptions.

To the very first of the four generalizations there are frequent exceptions as every experienced breeder knows. Like does not always beget like. Thus roan short-horned cattle do not always breed true. They produce their like, roans, in about 1 case out of 2 , but in the remaining case an all-red or an all white or a spotted red-and-white animal is likely to be produced. Blue Andalusian fowls are another well known exception to the rule that like produces like. Besides producing blue offspring, Andalusian fowls produce also black ones and white ones. Yellow mice are another unfixable variety of animal. They breed true in about 2 cases out of 3 . In the third case a black or brown pigmented animal is produced. Illustrations need not be multiplied; the literature of breeding is full of cases in which like has failed to produce like. Until quite recent years no satisfactory explanation of such cases has been forthcoming. Why a roan variety of cattle or a blue variety of fowl should be fixable to the extent of 50 per cent, whereas yellow mice should be fixable to 
the extent of 66 per cent was quite incomprehensible until a general law of color inheritance had been worked out.

The first serious attempt to formulate a general law of heredity was made in 1889 by Francis Galton, a pioneer in the study of genetics. He went about the matter in a systematic way, first collecting facts and then generalizing from them. In studying family records of the height of human beings he observed both that like begets like and that pedigree counts. For tall children are in general born only to tall parents, and the children are more certain to be tall if the grandparents also have been tall. He concluded that the resemblance of children to their grandparents was on the average only half as close as to their parents. Or to express it mathematically, if we call the parental influence one-half, that of the grandparents is onefourth; that of the great-grandparents one-eighth; and so on, each earlier generation of ancestors exerting only half as much influence as the next later one. This generalization, at first adopted tentatively only, Galton called the law of ancestral heredity. It states the facts of relative average size of ancestors and offspring about as well as we can state them at the present time, but offers no biological explanation of this relation. Nor does it inform us as to the probable limits of size variation among the children. This so-called law of Galton in reality rests on a false biological assumption, viz., that the character of the germ-cell regularly corresponds with that of the parent producing it. Galton himself recognized and pointed out this defect, but could devise no way of obviating it.

In order to test his empirical law more widely Galton in 1897 applied it to a case where it is now clearly not applicable, viz., to color inheritance in mammals. The particular case selected by him for study was unfortunately a peculiarly difficult one, viz., the inheritance of black spots in Bassett hounds. The result was that he reached erroneous conclusions.

The race of dogs studied was the Bassett hounds of Sir Everett Millais, a carefully bred race having the short crooked legs of a Dachshund combined with the spotted coat of a beagle. Careful records had been kept of the breeding of these dogs for many generations. In most respects they had been bred to a uniform type, but in color two different conditions.occurred. The dogs were all (or nearly all) spotted yellow-and-white. Part of them bore in addition spots of black, being thus tricolor yellow-black-and-white. Those without black spots were called by Galton non-tricolor.

Galton found on examination of the records that parents of one 
sort may produce young of the other sort as well as its own, though in smaller numbers. Neither kind, then, breeds entirely true, though each tends to produce its like. It was found further that parents produce a larger proportion of offspring like themselves if the grandparents also have been of that same sort. Hence there exists an apparent ancestral influence which Galton believed to be roughly approximated by his mathematical law. That this influence is apparent only, not real, I have shown elsewhere."

Galton had verified in this case as in that of human stature, the two, century-old generalizations, "Like begets like" and "Pedigree counts." He had attempted to measure the force of pedigree in his law of ancestral heredity, but not to account for it.

A more successful attempt to formulate a general law of heredity had been made some years earlier by Gregor Mendel, but this was

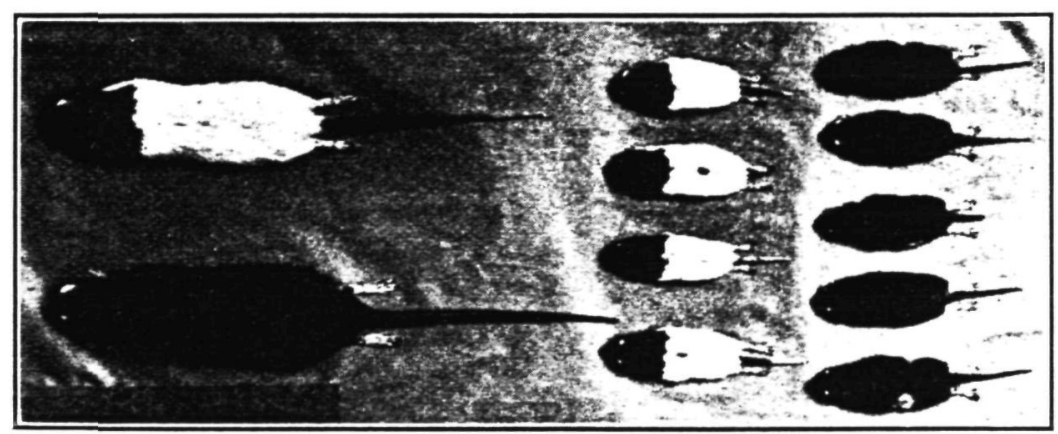

Fig. 1-A Famiti on Rats, tho Panents at the Letr, then On maphiro. a Binale Liteh AT ITI RIOEx

unknown to Galton as to other biologists of that time. We call it Mendel's law. In accordance with this law, the facts of color inheritance observed by Galton can be more fully explained.

It is a fundamental feature of this law that the characteristics of animals and plants are inherited as units. For example, in figure 1 are seen the skins of a family of rats; of the parents at the left, of their offspring at the right. The parents obviously differ in coloration, and the young are divided in a corresponding way into two groups approximately equal. Five of the young resemble one parent,

- The Lave of Berodity of Gelton and Mendel, and Bome Law Governing Raos Improvement

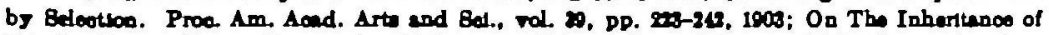

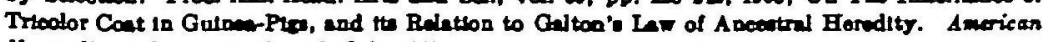
Natrakich, rol. 46, pp. 47-40, Jaly 1912. 
four resemble the other. The grouping of young into two classes has no relation to sex; each group includes both sexes. In both groups the animals are particolored, black and white, but in one group the black areas are more extensive than in the other. In one group the black head and back-stripe alone are black; these are called "hooded" rats. In the ocher group the entire dorsal surface is black; these are "Irish" rats. In neither group is the extent of the pigmentation absolutely uniform; it varies within narrow limits, yet the limits of the two groups are widely separated. No one would hesitate for a moment as to the grouping of any individual. If each group had been reared to maturity and had been allowed to breed separately, it would have been found that the hooded rats bred true, but that the Irish group produced again two sorts, Irish and hooded. If these grandchildren had in turn been sorted out into groups and bred separately, it would have been found that hooded rats would again produce only hooded young, whereas the Irish grandchildren would some of them again produce two sorts of young, Irish and hooded, while others would produce only Irish young. See the following diagram.

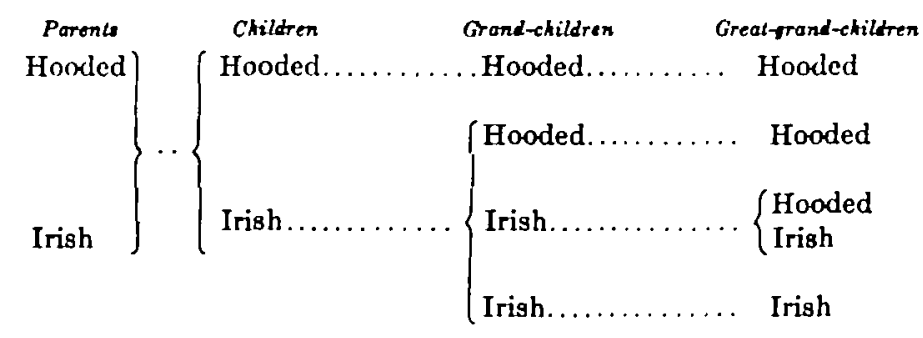

To make a long story short, this is a goot example of alternative or Mendelian inheritance. Irish is the dominant pattern, hooded recessive. Recessives always breed true, but dominants are of two sorts, those which breed true (called homozygous), and those which do not breed true (called heterozygoüs) but also produce recessives.

The original Irish parent in this family was heterozygous. In half its gametes the hooded condition was transmitted, in half the Irish condition. The Irish children were of the same sort, as would be found also part of the Irish grandchildren, but others of the Irish grandchildren would be found to be homozygous, transmitting nothing but the Irish character, and these would breed true. The noteworthy thing in this experiment is the demonstration that hooded and Irish patterns behave as alternative units, which may be brought 
together in the same individual by cross breeding and then separated out again in later generations.

If instead of crossing a hooded rat with an Irish one, as in the family already discussed, we cross it with a wild gray one, we obtain a different result. The children are all gray like the wild parent, but the grandchildren are of four sorts, gray-all-over, black-all-over, gray hooded, and black hooded, approximately in the proportions, $9: 3: 3$ $: 1$. By a cross two new color varieties have been created, the allblack and the gray hooded. It is evident that in this case, as in the foregoing, color-pattern is sharply alternative in inheritance, but the wild parent was homozygous in pattern not heterozygous, so all the children showed that same dominant pattern, and the hooded pattern reappeared first among the grandchildren, in one-fourth of the individuals. But among the hooded grandchildren, as well as among the self colored, both gray individuals and black ones occur. The same pattern occurs portrayed in different tints, gray or black. It is evident therefore that the gray color is alternative to black in the same way that self pattern is alternative to hooded. It is evident further that color and pattern are wholly independent, just as I may write the letter $A$ either in red or in blue crayon. There is no necessary relation between the letter which I write and the color in which I write it.

Likewise the hooded, Irish, and self patterns of rats may be portrayed either in black or in gray. Color and pattern in rats are therefore units independently transmitted in heredity and the varieties produced by crossing are nothing but new combinations of these same units. It is conceivable however that a new variety might be produced by actual alteration of one of these units, that the black for example might become blacker, or the gray might become lighter and that the modified units might still behave as alternatives. But the idea has somehow become prevalent among students of heredity that such modification is impossible, that Mendelian units cannot change. We have got in the habit of designating unit-characters by symbols, A, B, C, etc., and we have come to think of unit-characters as no more variable than these symbols. In reality no two organisms are ever exactly alike, and it is doubtful whether any unit-character is ever exactly the same in any two organisms. Some would frankly'admit this and yet maintain that what is transmitted is in every case the same, that is that the germinal basis of a unitcharacter is unchangeable, whatever may be true of its manifestation in the individual. The theoretical consequence of such a view is 
that selection can have no effect in modifying unit-characters. This conclusion is frankly avowed by many leading students of genetics. To show its unsoundness, it will be sufficient in a specific case to modify a unit-character. Many unit-characters have been so modified. I will describe a case in which the hooded pattern of rats has been changed by selection. This work has been done with the assistance of Dr. John-C. Phillips, though others of my associates bave shared in it to a lesser extent.

TABLE 1.-Results of Selection for Modification of the Coat-pattern of Hooded Rats.

\begin{tabular}{|c|c|c|c|c|}
\hline Dewoription of exlootion. & $\begin{array}{l}\text { Namber of } \\
\text { generman. }\end{array}$ & $\begin{array}{l}\text { A veracte srado } \\
\text { paronte. }\end{array}$ & $\begin{array}{l}\text { Aremeo predo } \\
\text { ofloprine. }\end{array}$ & $\begin{array}{l}\text { Number of } \\
\text { ofiprtot. }\end{array}$ \\
\hline 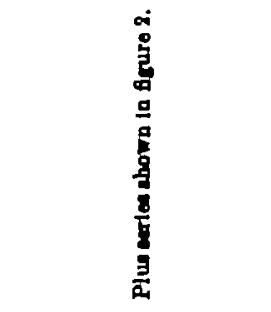 & $\begin{array}{c}1 \\
2 \\
3 \\
1 \\
5 \\
6 \\
7 \\
8 \\
0 \\
10 \\
11\end{array}$ & $\begin{array}{l}2.81 \\
2.62 \\
2.73 \\
3.00 \\
1.23 \\
3.80 \\
3.46 \\
3.75 \\
3.78 \\
3.86 \\
3.94\end{array}$ & $\begin{array}{l}2.05 \\
1.82 \\
2.81 \\
9.72 \\
2.80 \\
3.11 \\
3.20 \\
1.48 \\
3.64 \\
3.77 \\
2.76\end{array}$ & $\begin{array}{r}180 \\
471 \\
41 \\
414 \\
610 \\
801 \\
1,077 \\
1,408 \\
1,327 \\
706 \\
168\end{array}$ \\
\hline \multicolumn{4}{|c|}{ 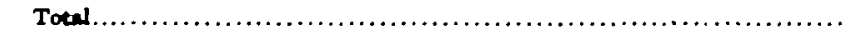 } & 7,58 \\
\hline 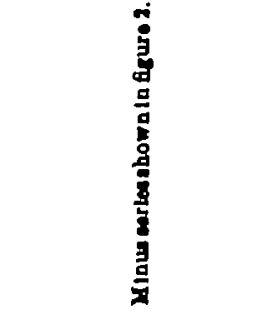 & $\begin{array}{r}1 \\
2 \\
3 \\
4 \\
5 \\
6 \\
7 \\
8 \\
9 \\
10 \\
11\end{array}$ & $\begin{array}{l}1.40 \\
1.41 \\
1.56 \\
1.69 \\
1.73 \\
1.86 \\
2.00 \\
1.06 \\
2.11 \\
2.18 \\
3.87\end{array}$ & $\begin{array}{l}1.00 \\
1.07 \\
1.18 \\
1.20 \\
1.41 \\
1.50 \\
1.70 \\
1.00 \\
1.08 \\
2.01 \\
2.18\end{array}$ & $\begin{array}{r}85 \\
138 \\
195 \\
500 \\
701 \\
1,253 \\
1,000 \\
1,053 \\
1,501 \\
1,400 \\
543\end{array}$ \\
\hline
\end{tabular}

Several years ago the experiment was begun of selecting from a stock of hooded rats extreme plus and minus variates and breeding the two selections separately. The most extreme variations of the hooded pattern at the outset are indicated roughly by grades -2 and +3 of figure 2. At first the two series overlapped in the regior. of grade 0 , but soon they ceased to do so and have drawn wider and wider apart ever since. In each generation the most extreme individuals were selected as parents. Table 1 shows the average grade of parents and offspring in each generation. But tables 2 and 3 show the average grade of offspring of parents of a particular grade 
in each generation. Attention is called to the following facts concerning the plus selection, that is, selection in the direction of blackness and solid color (table 2).

(1) At the outset the darkest parents we had were of grade 3, now we have parents of grade $5 \frac{1}{2}$, an all-black rat being grade 6 (the self condition). It is evident, therefore, that new grades of parents have appeared during the experiment; the table shows that they have come in gradually, 3 grade parents, in the third generation; $3 \frac{1}{2}$ grade parents, in the fourth generation; $3 \frac{7}{4}$ grade and 4 parents, in the fifth generation, and $4 \frac{1}{4}$ grade parents in the seventh generation. The modification has progressed through all intermediate stages between hooded and self, including Irish.

(2) An examination of the horizontal rows of the table shows that in any generation the higher the grade of the parents, the higher

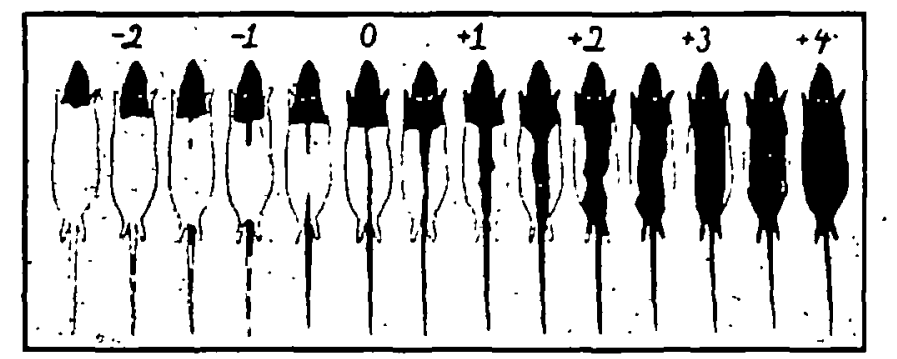

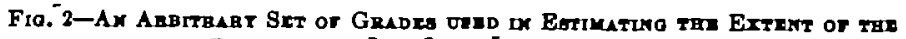

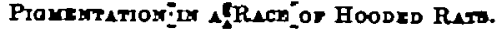

that of their offspring: In general therefore the somatic character of an animal in this series is an index of its genetic character. This makes change through selection possible.

(3) An examination of the vertical columns of the table shows that upon the appearance of a new grade of parents, the regression of the offspring is considerable, but with further selection it diminishes. I may add, what this table does not show: that with repeated selection it disappears altogether and is even reversed. That is, the lowest-grade offspring produced by selected high-grade parents do not regress downward toward the starting point of the series, but upward toward the mode of the parental generation. This indicates that the effects of the selection are permanent, for a new mode has been created toward which regression occurs.

In the minus selection series (table 3 ) the initial selection consisted of animals between -1 and -2 in pigmentation. Pairs of -2 par- 


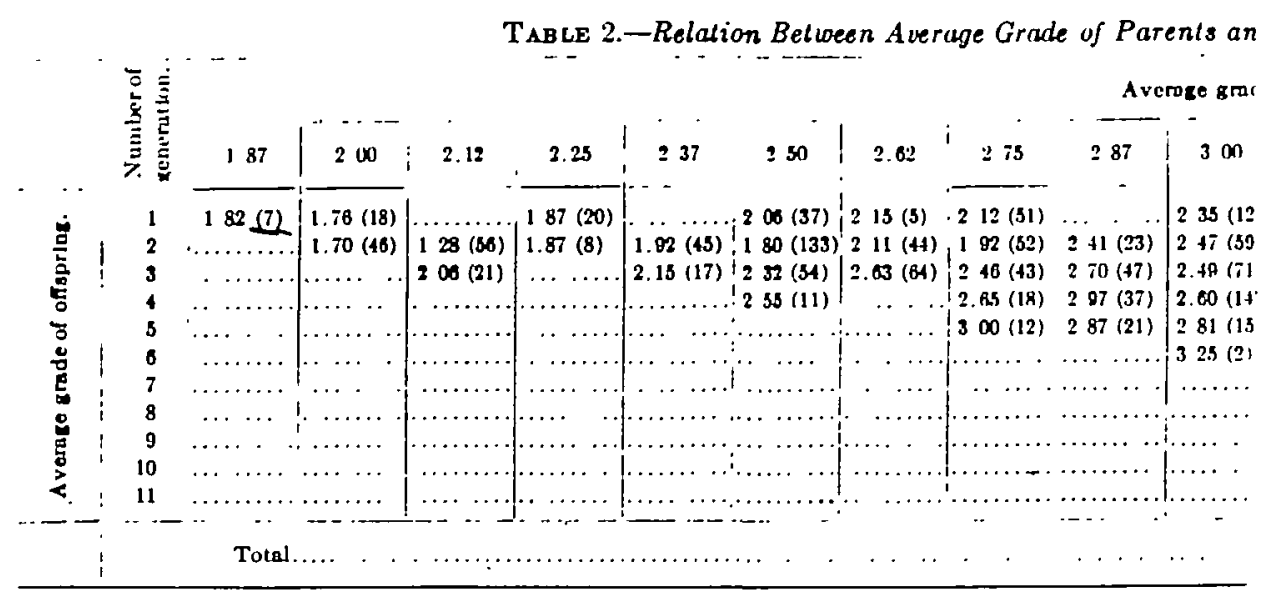

Note.-Figures in parentheses show number of offering on which the averages in each cass are hased.

ents occur for the first time in generation 4. Table 3 shows for this series the relation of average of offspring to grade of parents, and the results agree in every respect with those of table 2 . Note, that:

(1) New grades of parents appear as the experiment progresses. We how have parents pigmented only on the top and sides of the head, and with a large white spot on the forehead. If such rats have ever existed elsewhere at any time, I have failed to learn of them.

(2) The higher the grade of the parents in any generation, the higher that of their offspring.

(3) Regression grows less with repeated selection and finally changes its direction.

What is the conclusion of the whole matter? We find that hooded, Irish, and self patterns in rats, though Mendelizing as unit characters in relation to each other, are quantitative variations no more stable in character than intermediate stages; that any desired intermediate stage may be produced by selection alone, and when produced is fully as stable as any one of the three conditions named; that in a similar way stages of less pigmentation than any previously known in rats other than albinos have been produced and that there is every reason to suppose that this reduction can be carried forward by sclection until all color is eliminated from the coat.

Selection consequently is not a mere agency for the sorting out of unit variations (factors or genes); it is a creative agency by means of which unit characters can be modified and variation can be given 
leerage Grade of Offspring in Plus Selection Series.

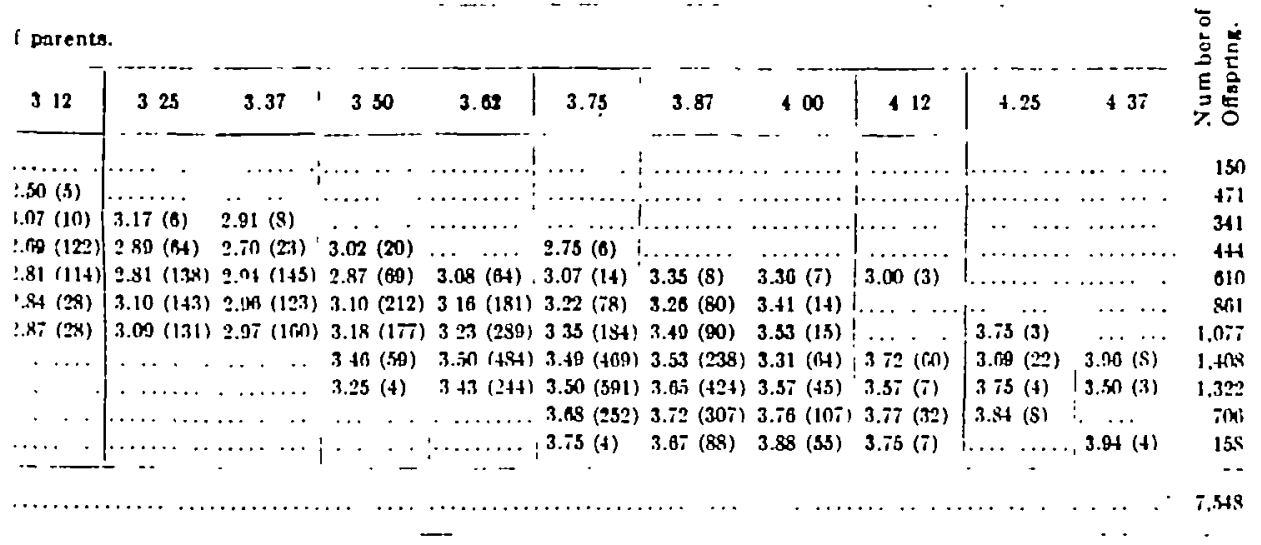

a particular direction, the only limits to its action being physiological limits.

But someone may say, you have considered merely one sort of unit character; grant that this is modifiable, what of the numerous other ones which have been described? In reply I can only say that I confine my attention to one for lack of space. I have not limited my study to one, and I have yet to meet with a unit-character which is not both variable and modifiable. It is only by closing one's eyes to minor variations that one can see gametic purity in heredity. Some recognize the occurrence of these minor variations but deny that they are of any consequence. This is the position of de Vrics and Bateson, Johannsen, and Jennings. Bateson for example in studying the inheritance of an extra toe in fowls recognized that it was not always equally well developed; nevertheless he grouped together in one class (having the extra-toe) all animals which developed even a trace of it, and placed in another class (as not possessing it) all which failed to develop an extra-toe, even though some of the latter actually did transmit the extra-toe. Now this is perhaps the best one can do in sorting out the material; but it is clearly unwarrantable to conclude that all fowls with an extra-toe possess a unit character or gene which is wanting in all birds which do not have the toe, or vice rersa. Clearly toe-character is inherited in various grades precisely as whitencss is in rats. Undoubtedly toe-character also is modifiable by selcction; indeed I have fully established this fact in guinea-pigs (1906). 
Axgrican Brbieders Magaztne

TaBLE 3.-Relation Botween Average Grade of Parenits and

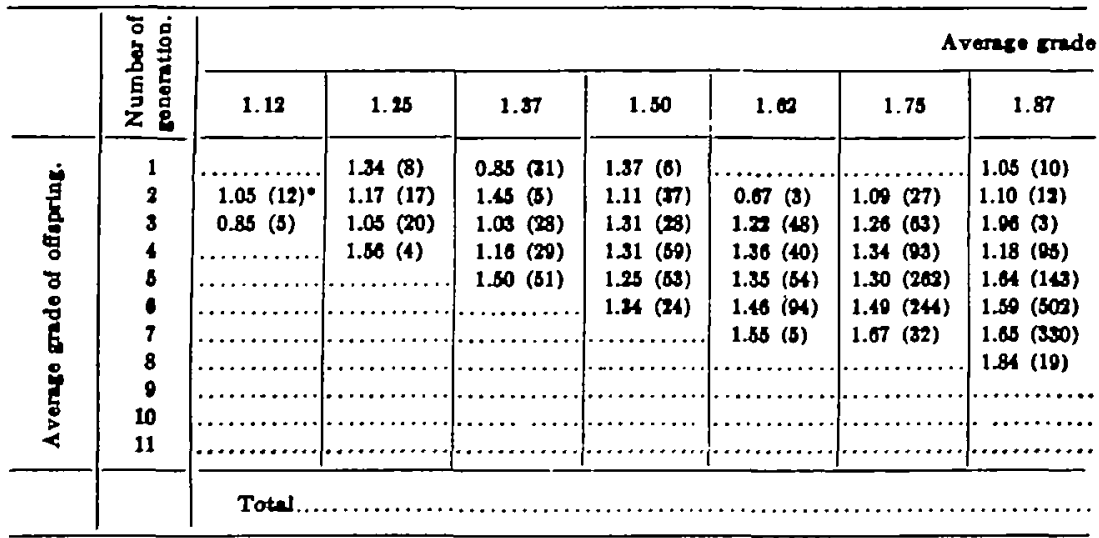

"Figuree in parentheree ahow numbers of offapring on which the everacee in each caso are based.

I therefore regard as unsubstantiated the genotype conception of heredity in which unit-characters are regarded as indestructible and unmodifiable entities. Organisms are not devoid of variability; neither are the unit-characters which they manifest devoid of variability, nor yet is the germinal basis of such unit-characters devoid of variability. Unit-characters may arise gradually as the result of repeated selection in a particular direction.

I have dwelt thus at some length upon this question because of its theoretical and practical importance. If unit-characters are immutable, then straight selection is a waste of time, and the only procedure for the breeder well worth while is to hybridize and thus seek new combinations of unit-characters. This view has been repeatedly presented in recent years, but has met with scant favor at the hands of experienced animal breeders.

Experienced breeders, to be sure, are not qualified to pass final judgment on a theoretical question, but a theory which will not work out in practice needs careful scrutiny; there is surely something wrong with it. If, however, unit-characters are modifiable, then selection is of value not only in the isolation of particular combinations of units, but also in the improvement of the units themselves.

Mendel's law, in its broad general features, does stand the test of practice. It represents a fundamental general law of heredity. Many of the characteristics of animals and plants are transmitted substantially as units and are therefore capable of recombination in the form of new varieties through the agency of crossing. By apply- 
A verage Grads of Offspring in Minus Selection Series.

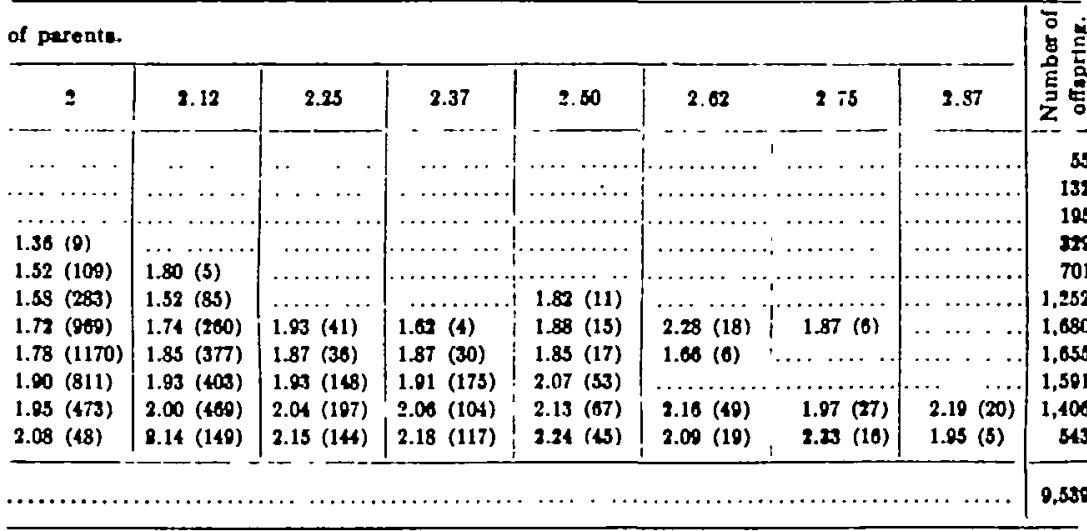

ing Mendel's law to specific cases one is able to predict with a considerable degree of accuracy what combinations will result from a particular cross and in what proportions these will be produced. Such a practical test is the best possible evidence of the correctness of a theory. Mendel's kaw throws light on each of the generalizations of empirical animal breeding previously enumerated:

It throws light on those recognized exceptions to the generalization that like begets like, and shows under what circumstances those exceptions are to be expected.

It shows why and when pedigree counts, and under what circumstances a knowledge of pedigree is of no consequence whatever.

It shows why inbreeding brings uniformity of type, and crossbreeding destroys it.

Mendel's law is then a first step towiard the establishment of a science of animal breeding. But it is only a first step on a long and weary road, and we must be careful not to misinterpret or misapply it. Otherwise we are liable to be turned aside from the direct road of progress. We must not, for example, conclude on insufficient evidence that unit-characters possess an immutability which organisms do not possess. It is the purpose of this paper to insist on this point. Further we are not yet warranted in concluding that all inheritance is unit-character inheritance. A too sweeping generalization of this sort may also lead us astray. Let us proceed with enthusiasm, but with caution, noting well our landmarks.

The practical utility of Mendel's law is much greater to the plant 
breeder than to the animal breeder, because the plant-breeder is concerned largely with the production of a very few first generation or second generation hybrids of merit, which are then multiplied indefinitely by asexual means or self fertilization. In the case of the domesticated animals such methods of multiplication are impossible. Every individual produced has two parents, and purity of race in the parents is indispensable to uniformity of type in the progeny.

As a theoretical foundation principle Mendel's law is equally valuable to animal breeders and to plant breeders.

\title{
HORSES AND HORSE BREEDING*
}

\author{
H. K. Bush-BrowN
}

Washington, D. C.

In a former article published in the American Breeders Magazine, I suggested that the best race horses, both trotters and runners, be studied anatomically in their living active form, and from the skeleton after death, as a means of mathematically determining what differences there are in structure. This would enable us to not only establish a method of defining types but also to ascertain which structural propositions are the most favorable to speed and endurance, and in what way the runner differs from the trotter. Every horseman recognizes the differences of proportion at a glance and by instinct, but so far as I know they have not been reduced to mathematical and comparable terms.

No one will question that the separate types of horses which we breed and keep for specific purposes, are the results of selective breeding, and that the differences between breeds are largely a matter of differences in the proportions of the structure of the skeleton. And this suggests the need of an accurate and reliable method of measuring the bodies of individuals, which will make full allowance for variations in size, so that not only large and small individuals of the same breed may become comparable, but also individuals belonging to different breeds, and even the same individual in different stages of growth. Such a method must clearly be based upon a unit common to all individuals, and upon a comparison of proportions rather than upon absolute measurements.

- Thle the the weond article of the wrtes on Horme and Horeo-Breding begun by the suthor in A meriean Breders Magarine, rol. 11, no. 2, wad no. 3. 